\title{
AN OUTPUT SENSITIVITY PROBLEM FOR A CLASS OF FRACTIONAL ORDER DISCRETE-TIME LINEAR SYSTEMS
}

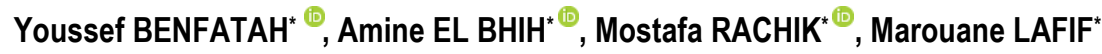 \\ *Faculty of Sciences Ben M'Sik, Department of Mathematics and Computer Science, \\ Hassan II University, Casablanca, Sidi Othman BP 7955, Morocco \\ youssef.benfatah@gmail.com, elbhihamine@gmail.com, m_rachik@yahoo.fr, marouane8@gmail.com,
}

received 7 February 2021, revised 16 September 2021, accepted 20 September 2021

Abstract: Consider the linear discrete-time fractional order systems with uncertainty on the initial state $\begin{cases}\Delta^{\alpha} x_{i+1}=A x_{i}+B u_{i}, & i \geq 0 \\ x_{0}=\tau_{0}+\hat{\tau}_{0} \in \mathbb{R}^{n}, & \hat{\tau}_{0} \in \Omega, \\ y_{i}=C x_{i}, & i \geq 0\end{cases}$ where $\mathrm{A}, \mathrm{B}$ and $\mathrm{C}$ are appropriate matrices, $\mathrm{x}_{0}$ is the initial state, $\mathrm{y}_{\mathrm{i}}$ is the signal output, $\alpha$ the order of the derivative, $\tau_{0}$ and $\hat{\tau}_{0}$ are the known and unknown part of $\mathrm{x}_{0}$, respectively, $\mathrm{u}_{\mathrm{i}}=\mathrm{Kx}_{\mathrm{i}}$ is feedback control and $\Omega \subset \mathbb{R}^{\mathrm{n}}$ is a polytope convex of vertices $\mathrm{w}_{1}, \mathrm{w}_{2}, \ldots, \mathrm{w}_{\mathrm{p}}$. According to the Krein-Milman theorem, we suppose that $\hat{\tau}_{0}=\sum_{j=1}^{p} \alpha_{j} w_{j}$ for some unknown coefficients $\alpha_{1} \geq 0, \ldots, \alpha_{p} \geq$ 0 such that $\sum_{j=1}^{p} \alpha_{j}=1$. In this paper, the fractional derivative is defined in the Grünwald-Letnikov sense. We investigate the characterisation of the set $\chi\left(\hat{\tau}_{0}, \epsilon\right)$ of all possible gain matrix $\mathrm{K}$ that makes the system insensitive to the unknown part $\hat{\tau}_{0}$, which means $\chi\left(\hat{\tau}_{0}, \epsilon\right)=\left\{\mathrm{K} \in \mathbb{R}^{\mathrm{m} \times \mathrm{n}} /\left\|\frac{\partial \mathrm{y}_{\mathrm{i}}}{\partial \alpha_{\mathrm{j}}}\right\| \leq \epsilon, \forall \mathrm{j}=1, \ldots, \mathrm{p}, \forall \mathrm{i} \geq 0\right\}$, where the inequality $\left\|\frac{\partial \mathrm{y}_{\mathrm{i}}}{\partial \alpha_{\mathrm{j}}}\right\| \leq \epsilon$ showing the sensitivity of $\mathrm{y}_{\mathrm{i}}$ relatively to uncertainties $\left\{\alpha_{\mathrm{j}}\right\}_{\mathrm{j}=1}^{\mathrm{p}}$ will not achieve the specified threshold $\epsilon>0$. We establish, under certain hypothesis, the finite determination of $\chi\left(\hat{\tau}_{0}, \epsilon\right)$ and we propose an algorithmic approach to made explicit characterisation of such set.

Key words: fractional order systems, output sensitivity, discrete-time systems, maximal output set admissible uncertainty

\section{INTRODUCTION}

Fractional calculus is an extended version of the traditional integer order calculus in which the definition of derivatives is given to a non-integer order. The non-integer derivative concept is used increasingly for modelling of real systems behaviour in different disciplines of engineering and science (Debnath, 2003). These systems have long-memory transients and hereditary properties that can be more accurately described by fractional-order models. In the recent past, there has been an increasing focus on discretetime fractional systems (Kaczorek, 2007; Kaczorek, 2008; Sierociuk and Dzieliński, 2006; Ferreira and Torres, 2011). Some important developments of the theory of fractional calculus are presented in Kilbas et al., (2006) and Oldham and Spanier (1974).

On the other hand, undesirable parameters appeared during modelling a system; consequently such parameters could have an impact on various elements of the system including initial conditions, control, dynamic, and observations. To deal with this problem, a variety of approaches have been developed by researchers, including the theory of sentinel (Lions), the detectability in Franklin (2001) and Ogata (1995), identifiability in Thomson (2007); Kauffmann and Bretthawer; and Robert and Graham (2007), the $\mathrm{H}_{\infty}$ control theory in Chi-Tsong) 2008) and the frequency domain and robustness (Rosario, 2005; Gu et al., 2005).

\subsection{Related work}

Concerning the sensitivity of the system output to the disturbance, the readers can refer to Larrache et al. (2020); Rachik and Lhous (2016); Balatif et al. (2016); and Chraïbi et al. (2006). Larrache et al. (2020) considered an infinite dimensional linear system described as

$\left\{\begin{array}{l}\dot{x}(t)=A x(t), \quad t \geq 0 \\ x(0)=x_{0}=\alpha 1_{\omega_{1}}+\beta 1_{\omega_{2}} \\ y_{i}=C x_{i}+D v_{i}, \quad i \geq 0,\end{array}\right.$

where $\mathrm{x}(\mathrm{t}) \in \mathrm{L}^{2}(\Omega), 1_{\omega_{\mathrm{i}}}$ is the indicator function, and $\Omega$ is an open bounded of $\mathbb{R}^{\mathrm{n}}$ such that $\Omega=\omega_{1} \cup \omega_{2}$ and $\omega_{1} \cap \omega_{2}=$ $\varnothing$. The operator A generates a continuous strongly semigroup $\{\mathrm{S}(\mathrm{t})\}_{\mathrm{t} \geq 0}$ on the space $\mathrm{L}^{2}(\Omega), \mathrm{V}_{\mathrm{i}}=\mathrm{Kx}_{\mathrm{i}}, \mathrm{i} \geq 0$ feedback control, $\mathrm{K} \in \mathcal{L}\left(\mathrm{L}^{2}(\Omega), \mathbb{R}^{\mathrm{p}}\right)$. The initial state $\mathrm{x}_{0}$ is supposed to be known on $\omega_{1}$ but not on $\omega_{2}$. The authors suggest a method to identify within these controls law $v_{i}, \quad i \geq 0$ making the system insensitive to the impact of these unknown parameters $\beta$. The case of the disturbances infecting a linear system's initial state has been investigated in Kolmanovsky and Gilbert (1998) and Namerikawa et al. (2004).

The sentinel theory was initiated and developed by Lions in (Lions, 1992; Lions, 1988). Sawadogo (2020) have used the 
sentinel method to control the migration by studying the dynamics of a single species population and whose initial distribution is unknown.

In the literature, the notion of maximal output set is of great significant in the area of control and analysis of linear and nonlinear systems. Numerous studies have been carried out on the construction of the maximal output set (El Bhih et al., 2020; Yamamoto, 2019; Osorio and Ossareh, 2018; Abdelhak and Rachik, 2019; Gilbert and Tan, 1991). Different algorithms have been included in the research literature to specify the maximal state constraint sets (Gilbert and Tan, 1991; Dórea and Hennet, 1996).

\subsection{Problem statement}

A fundamental requirement for most dynamical systems is to keep a given output function insensitive to the disturbances. In this paper, we suppose that the initial state of the system is composed of two parts: the unknown part noted as $\hat{\tau}_{0}$ and the known part noted as $\tau_{0}$. We propose a new technique to characterise the set $\chi\left(\hat{\tau}_{0}, \epsilon\right)$ of all possible gain matrix $\mathrm{K}$, based on the maximal output set $\Upsilon(\mathrm{K}, \epsilon)$, so that the sensitivity of the resulting system output would be relatively tolerable, that is, make the system insensitive to the unknown part $\hat{\tau}_{0}$ of the initial state $x_{0}$, of commensurate fractional order discrete-time controlled linear systems which are modelled by equations of fractional state space. To the best of our knowledge, the output sensitivity of such systems has not been treated yet. We propose some new sufficient conditions that ensure the finite determination of the set $\chi\left(\hat{\tau}_{0}, \epsilon\right)$. Moreover, we present an effective algorithm to obtain the maximal output set $\Upsilon(\mathrm{K}, \epsilon)$ and then the set $\chi\left(\hat{\tau}_{0}, \epsilon\right)$. The algorithm having theoretical convergence properties are provided in Gilbert and Tan (1991).

Therefore, we study a discrete-time linear control systems of fractional order with uncertainty on the initial state, evolving on $\mathbb{R}^{\mathrm{n}}$. More precisely, we consider the system as

$\left\{\begin{array}{l}\Delta^{\alpha} \mathrm{x}_{\mathrm{i}+1}=A \mathrm{x}_{\mathrm{i}}+\mathrm{Bu}_{\mathrm{i}}, \quad \mathrm{i} \geq 0 \\ \mathrm{x}_{0}=\tau_{0}+\hat{\tau}_{0} \in \mathbb{R}^{\mathrm{n}}\end{array}\right.$

The corresponding output is

$\mathrm{y}_{\mathrm{i}}=\mathrm{Cx}_{\mathrm{i}}, \quad \mathrm{i} \geq 0$

where $\mathrm{A}$ is a matrix of order $\mathrm{n} \times \mathrm{n}$, the system dynamics, $\mathrm{B}$ is the input matrix of order $\mathrm{n} \times \mathrm{m}$ and $\mathrm{C}$ is the output matrix of order $\mathrm{p} \times \mathrm{n} ; \alpha$ is the order of the derivative, $\tau_{0}$ is the known part, $\hat{\tau}_{0}$ is the unknown part and $\mathrm{u}_{\mathrm{i}}=\mathrm{Kx}_{\mathrm{i}}$ is the feedback control.

The remainder of this paper is organised as follows: In Section 2 , we recall a fundamental definition of fractional derivatives (Grünwald-Letnikov), then we consider the discrete-time system proposed in Dzieliński and Sierociuk (2005). With uncertainty on the initial state, we recall the Krein-Millman theorem and some definitions. Section 3 deals with the characterisation of the set of all possible gain matrices which make the system insensitive to the unknown part, based on the maximal output set. New sufficient conditions are provided to show the finite determination of such set. In Section 4, we propose an algorithm approach to identify the index of admissibility. We illustrate some examples and numerical simulations in Section 5 . We conclude the paper by in Section 6.
Notation: $\mathbb{R}^{\mathrm{n}}$ the set of real vectors with $\mathrm{n}$ components, $\mathcal{L}\left(\mathbb{R}^{n}, \mathbb{R}^{\mathrm{n}}\right)$ the set of real matrices of order $\mathrm{n} \times \mathrm{n}, \mathbb{N}$ the set of nonnegative integers, $\sigma_{\mathrm{s}}^{\mathrm{k}}=\{\mathrm{s}, \mathrm{s}+1, \ldots, \mathrm{k}\} \subset \mathbb{N}$ where $\mathrm{s} \leq \mathrm{k}$, $\mathrm{I}_{\mathrm{n}}$ denotes the identity matrix in $\mathcal{L}\left(\mathbb{R}^{\mathrm{n}}, \mathbb{R}^{\mathrm{n}}\right)$. The components of a vector $b$ are noted as $(b)_{j}$ and the components of a matrix $A$ are noted as $(\mathrm{A})_{\mathrm{ij}}$.

\section{FRACTIONAL CALCULUS AND DYNAMIC MODELS}

To begin our work, we will introduce certain basic notions concerning the fractional calculus that are utilised along the paper. The definition of the discrete fractional derivative in this paper is as follows: Grünwald-Letnikov (Oldham and J. Spanier, 1974; Podlubny, 1999).

Definition 1. The Grünwald-Letnikov (backward) difference of fractional order $\alpha$ of the function $\mathrm{x}($.$) at \mathrm{k} \in[0,+\infty$ [ is given as

$\Delta^{\alpha} \mathrm{x}(\mathrm{k})=\frac{1}{\mathrm{~h}^{\alpha}} \sum_{\mathrm{j}=0}^{\mathrm{k}}(-1)^{\mathrm{j}}\left(\begin{array}{l}\alpha \\ \mathrm{j}\end{array}\right) \mathrm{x}(\mathrm{k}-\mathrm{j})$

where the order of the derivative $\alpha \in] 0,1\left[, \mathrm{~h} \in \mathbb{R}^{*+}\right.$ is a sampling period taken equal to unity in all what follows, and $\mathrm{k} \in \mathbb{N}$ is the number of samples for which the approximation of the derivative is calculated.

The term $\left(\begin{array}{l}\alpha \\ j\end{array}\right)$ in Definition 2 can be obtained from the following relation:

$\left(\begin{array}{l}\alpha \\ j\end{array}\right)= \begin{cases}1 & \text { for } j=0, \\ \frac{\alpha(\alpha-1) \ldots(\alpha-j+1)}{j !} & \text { for } j>0 .\end{cases}$

Let us consider now the discrete-time linear fractional order system as defined in Dzieliński and Sierociuk (2005), described as

$\left\{\begin{array}{l}\Delta^{\alpha} \mathrm{x}_{\mathrm{i}+1}=A \mathrm{x}_{\mathrm{i}}+\mathrm{Bu}_{\mathrm{i}}, \\ \mathrm{x}_{0}=\tau_{0}+\hat{\tau}_{0} \in \mathbb{R}^{\mathrm{n}}\end{array}\right.$

where $\mathrm{A} \in \mathcal{L}\left(\mathbb{R}^{\mathrm{n}}, \mathbb{R}^{\mathrm{n}}\right)$ is the system dynamics, $\mathrm{B} \in \mathcal{L}\left(\mathbb{R}^{\mathrm{m}}, \mathbb{R}^{\mathrm{n}}\right)$ is the input matrix and $C \in \mathcal{L}\left(\mathbb{R}^{n}, \mathbb{R}^{p}\right)$ is the output matrix; $\alpha$ is the order of the derivative, $\tau_{0}$ is the known part, $\hat{\tau}_{0}$ is the unknown part and

$x_{i}=\left(\begin{array}{l}x_{i}^{1} \\ x_{i}^{2} \\ \vdots \\ x_{i}^{n}\end{array}\right) \in \mathbb{R}^{n}$

is the state variable.

The associated output function is

$\mathrm{y}_{\mathrm{i}}=\mathrm{Cx}_{\mathrm{i}} \in \mathbb{R}^{\mathrm{p}}$

Its initial value is denoted by $\mathrm{x}_{0}$. The control low (feedback control) is

$\mathrm{u}_{\mathrm{i}}=\mathrm{Kx}_{\mathrm{i}} \in \mathbb{R}^{\mathrm{m}}$.

In this system, the differentiation order $\alpha$ is taken as the same for all the state variables $x_{i}^{j}, j=1,2, \ldots, n$, that is

$\Delta^{\alpha} \mathrm{X}_{\mathrm{i}}=\left(\begin{array}{l}\Delta^{\alpha} \mathrm{x}_{\mathrm{i}}^{1} \\ \Delta^{\alpha} \mathrm{x}_{\mathrm{i}}^{2} \\ \vdots \\ \Delta^{\alpha} \mathrm{x}_{\mathrm{i}}^{\mathrm{n}}\end{array}\right)$ 
This is referred to as commensurate order. We will propose a technique to determine among these controls as low which makes the system insensitive to the effect of the unknown part $\hat{\tau}_{0}$. as

We replace $\Delta^{\alpha} \mathrm{X}_{\mathrm{i}+1}$ by its value; system (6) could be rewritten

$$
\left\{\begin{array}{l}
\mathrm{x}_{\mathrm{i}+1}=\sum_{\mathrm{j}=0}^{\mathrm{i}} \mathrm{A}_{\mathrm{j}} \mathrm{x}_{\mathrm{i}-\mathrm{j}} \\
\mathrm{x}_{0}=\tau_{0}+\hat{\mathrm{\tau}}_{0} \in \mathbb{R}^{\mathrm{n}}
\end{array}\right.
$$

where

$\mathrm{A}_{0}=\mathrm{A}+\mathrm{BK}+\alpha \mathrm{I}_{\mathrm{n}}$

and

$A_{j}=-(-1)^{j+1}\left(\begin{array}{l}\alpha \\ j+1\end{array}\right) I_{n}, \quad \forall j \geq 1$.

Remark 1. The model described in (8) can be classified as a discrete-time system with a time-delay in the state. For practical use, the number of simple taken into consideration needs to be reduced to the predefined number $\mathrm{L}$ called the memory length and $\mathrm{x}_{\mathrm{i}}=0$ for $\mathrm{i}<0$ (Dzieliński and Sierociuk, 2008).

Thus, system (8) becomes

$$
\left\{\begin{array}{l}
x_{i+1}=\sum_{j=0}^{L} A_{j} x_{i-j} \\
x_{0}=\tau_{0}+\hat{\tau}_{0} \in \mathbb{R}^{n}
\end{array}\right.
$$

Definition 2. The system given by (6) could be rewritten as an infinite dimensional system taking the form

$$
\left(\begin{array}{l}
x_{i+1} \\
x_{i} \\
x_{i-1} \\
\vdots
\end{array}\right)=\widetilde{A}\left(\begin{array}{l}
x_{i} \\
x_{i-1} \\
x_{i-2} \\
\vdots
\end{array}\right)+\widetilde{B} u_{i} \quad, \quad y_{i}=\widetilde{C}\left(\begin{array}{l}
x_{i} \\
x_{i-1} \\
x_{i-2} \\
\vdots
\end{array}\right)
$$

where $\widetilde{\mathrm{A}}=\left(\begin{array}{cccc}\mathrm{A}+\alpha \mathrm{I}_{\mathrm{n}} & \mathrm{A}_{1} & \mathrm{~A}_{2} & \cdots \\ \mathrm{I}_{\mathrm{n}} & 0 & 0 & \cdots \\ 0 & \mathrm{I}_{\mathrm{n}} & 0 & \cdots \\ \vdots & \vdots & \vdots & \vdots\end{array}\right), \widetilde{\mathrm{B}}=\left(\begin{array}{c}\mathrm{B} \\ 0 \\ 0 \\ \vdots\end{array}\right) \quad$ and $\tilde{\mathrm{C}}=\left(\begin{array}{llll}\mathrm{C} & 0 & 0 & \cdots\end{array}\right)$.

Theorem 1 (Dzieliński-Sierociuk, 2008) The system given by definition (2) is asymptotically stable if and only if $\|\tilde{A}\|<1$, where $\|$.$\| denotes the matrix norm defined as \max \left|\lambda_{i}\right|$, where $\lambda_{i}$ is the $i^{\text {th }}$ eigenvalue of the matrix $\tilde{A}$.

The general solution of (11) (Buslowicz, 1983) is given as

$\mathrm{x}_{\mathrm{i}}=\mathrm{G}_{\mathrm{i}} \mathrm{x}_{0}$

where

$G_{i}=\left\{\begin{array}{lll}I_{n} & \text { if } \quad i=0 \\ \sum_{j=0}^{L} A_{j} G_{i-1-j} & \text { if } \quad i \geq 1 & \end{array}\right.$

with $\mathrm{G}_{\mathrm{i}}=0, \quad \forall \mathrm{i}<0$.

Remark 2 From (12) and (13) for $\alpha=1$ we have

$\mathrm{x}_{\mathrm{i}}=(\mathrm{A}+\mathrm{I}+\mathrm{BK})^{\mathrm{i}} \mathrm{x}_{0}$

for which the corresponding solution of the linear discrete-time systems is

$\left\{\begin{array}{l}\mathrm{x}_{\mathrm{i}+1}=(\mathrm{A}+\mathrm{I}) \mathrm{x}_{\mathrm{i}}+\mathrm{Bu}_{\mathrm{i}}, \quad \mathrm{i} \geq 0 \\ \mathrm{x}_{0} \in \mathbb{R}^{\mathrm{n}}\end{array}\right.$
Remark 3 In the case of noncommensurate order we have

$\left\{\begin{array}{l}\mathrm{x}_{\mathrm{k}+1}=\sum_{\mathrm{j}=0}^{\mathrm{k}} \mathrm{A}_{\mathrm{j}} \mathrm{x}_{\mathrm{k}-\mathrm{j}} \\ \mathrm{x}_{0}=\tau_{0}+\hat{\tau}_{0} \in \mathbb{R}^{\mathrm{n}} \\ \mathrm{y}_{\mathrm{k}}=\mathrm{Cx}_{\mathrm{k}}, \quad \mathrm{k} \geq 0\end{array}\right.$

where the matrices $A_{j}$ are given as

$\mathrm{A}_{0}=\mathrm{A}+\mathrm{BK}+\operatorname{diag}\left(\left(\begin{array}{l}\alpha_{1} \\ 1\end{array}\right), \ldots,\left(\begin{array}{l}\alpha_{\mathrm{n}} \\ 1\end{array}\right)\right)$

and for all $\mathrm{j} \geq 1$

$A_{j}=-(-1)^{j+1} \operatorname{diag}\{\overbrace{\left(\begin{array}{l}\alpha_{1} \\ j+1\end{array}\right), \ldots,\left(\begin{array}{c}\alpha_{n} \\ j+1\end{array}\right)}^{n-\text { times }}\}$.

If $A \subset \mathbb{R}^{n}$, then the convex hull of $A$ is the smallest convex set containing $\mathrm{A}$, that is, it consists of all finite convex combinations of elements in $\mathrm{A}$. The closed convex hull of $\mathrm{A}$ is the closure of the convex hull of A. Now, we present the theorem of KreinMilman (see Haim Brezis).

Theorem 2 (Krein-Milman) Let $K \subset \mathbb{R}^{n}$ be a compact convex set. Then $K$ coincides with the closed convex hull of its extreme points. In the following, we will assume that the unknown part $\hat{\tau}_{0} \in \Omega$, where the set $\Omega \subset \mathbb{R}^{n}$ is a polytope convex of vertices $w_{1}, w_{2}, \ldots, w_{p}$. According to Krein-Milman theorem, the unknown part $\hat{\tau}_{0}$ could be written as follows:

$\hat{\tau}_{0}=\sum_{\mathrm{j}=1}^{\mathrm{p}} \alpha_{\mathrm{j}} \mathrm{w}_{\mathrm{j}}$.

for some unknown coefficients $\alpha_{1} \geq 0, \ldots, \alpha_{p} \geq 0$, such that $\sum_{\mathrm{j}=1}^{\mathrm{p}} \alpha_{\mathrm{j}}=1$.

Definition 3. (Larrache, 2020) An unknown part $\hat{\tau}_{0}$ is said to be $\epsilon$-tolerable if the corresponding output satisfies the following condition:

$\left\|\frac{\partial y_{i}}{\partial \alpha_{j}}\right\| \leq \epsilon, \quad \forall \mathrm{j} \in \sigma_{1}^{p}, \quad \forall \mathrm{i} \geq 0$.

Otherwise, $\hat{\tau}_{0}$ is said to be $\epsilon$-intolerable.

Definition 4. For a given $\epsilon>0$, and a gain matrix $K \in \mathbb{R}^{\mathrm{m} \times \mathrm{n}}$, the set

$\Upsilon(\mathrm{K}, \epsilon)=\left\{\mathrm{x} \in \mathbb{R}^{\mathrm{n}} / \quad\left\|\mathrm{y}_{\mathrm{i}}\right\|=\left\|\mathrm{CG}_{\mathrm{i}} \mathrm{x}\right\| \leq \epsilon, \quad \forall \mathrm{i} \geq 0\right\}$

is called the maximal output set.

Our goal is to characterise the set $\chi\left(\hat{\tau}_{0}, \epsilon\right)$ of all gain matrices $\mathrm{K}$, which makes the systems insensitive to the unknown part $\hat{\tau}_{0}$, to be explicit as

$\chi\left(\hat{\tau}_{0}, \epsilon\right)=\left\{\mathrm{K} \in \mathbb{R}^{\mathrm{m} \times \mathrm{n}} /\left\|\frac{\partial \mathrm{y}_{\mathrm{i}}}{\partial \alpha_{\mathrm{j}}}\right\| \leq \epsilon, \quad \forall \mathrm{j} \in \sigma_{1}^{\mathrm{p}}, \quad \forall \mathrm{i} \geq\right.$ $0\} .(22)$

On the other hand, we have

$\frac{\partial \mathrm{y}_{\mathrm{i}}}{\partial \alpha_{\mathrm{j}}}=\frac{\partial \mathrm{CG}_{\mathrm{i}}\left(\tau_{0}+\hat{\mathrm{\tau}}_{0}\right)}{\partial \alpha_{\mathrm{j}}}=\mathrm{CG}_{\mathrm{i}} \mathrm{W}_{\mathrm{j}}, \quad \forall \mathrm{j} \in \sigma_{1}^{\mathrm{p}}, \quad \forall \mathrm{i} \geq 0$.

This leads to

$\chi\left(\hat{\tau}_{0}, \epsilon\right)=\left\{\mathrm{K} \in \mathbb{R}^{\mathrm{m} \times \mathrm{n}} /\left\|\mathrm{CG}_{\mathrm{i}} \mathrm{w}_{\mathrm{j}}\right\| \leq \epsilon, \forall \mathrm{j} \in \sigma_{1}^{\mathrm{p}}, \forall \mathrm{i} \geq 0\right\}$. (24)

In Remark 4, we will show the interest of introducing the set $\Upsilon(\mathrm{K}, \epsilon)$ in the characterisation of $\chi\left(\hat{\tau}_{0}, \epsilon\right)$. 
Remark 4 The set $\chi\left(\widehat{\tau}_{0}, \epsilon\right)$ can be rewritten as

$\chi\left(\hat{\tau}_{0}, \epsilon\right)=\left\{K \in \mathbb{R}^{m \times n} / w_{j} \in \Upsilon(K, \epsilon), \quad \forall j \in \sigma_{1}^{p}\right\}$.

Therefore, system (6) is insensitive to the unknown part $\hat{\tau}_{0}$ if and only if $\mathrm{w}_{\mathrm{j}} \in \Upsilon(\mathrm{K}, \epsilon), \quad \forall \mathrm{j} \in \sigma_{1}^{\mathrm{p}}$. In order to characterise the set $\Upsilon(K, \epsilon)$ and then our set $\chi\left(\hat{\tau}_{0}, \epsilon\right)$, we introduce the sets $\Upsilon^{\mathrm{k}}(\mathrm{K}, \epsilon), \quad \mathrm{k} \geq 0$ defined as

$\Upsilon^{\mathrm{k}}(\mathrm{K}, \epsilon)=\left\{\mathrm{x} \in \mathbb{R}^{\mathrm{n}} / \quad\left\|\mathrm{y}_{\mathrm{i}}\right\|=\left\|\mathrm{CG}_{\mathrm{i}} \mathrm{x}\right\| \leq \epsilon, \quad \forall \mathrm{i} \in \sigma_{0}^{\mathrm{k}}\right\}$.

\section{CHARACTERISATION OF THE MAXIMAL OUTPUT SET $\mathbf{Y}(\mathbf{K}, \boldsymbol{\epsilon})$}

The main purpose of this section is to characterise, under certain hypothesis, the maximal output set $\Upsilon(\mathrm{K}, \epsilon)$ and then the set $\chi\left(\hat{\tau}_{0}, \epsilon\right)$. We prove the finite determination of the set $\Upsilon(\mathrm{K}, \epsilon)$ and then the set $\chi\left(\hat{\tau}_{0}, \epsilon\right)$, and this leads to the algorithmic procedure for the computation of such set.

Definition 5. (Gilbert, 1991; Rachik, 2002) The set $\Upsilon(K, \epsilon)$ is said to be finitely determined, if there exists an integer $\mathrm{k}$ such that $\Upsilon(K, \epsilon)=\Upsilon^{\mathrm{k}}(\mathrm{K}, \epsilon)$. Let $\mathrm{k}^{*}$ be the smallest integer such that $\Upsilon(\mathrm{K}, \epsilon)=\Upsilon^{\mathrm{k}^{*}}(\mathrm{~K}, \epsilon)$; we call $\mathrm{k}^{*}$ the admissibility index.

Remark $5\left\{Y^{\mathrm{k}}(\mathrm{K}, \epsilon)\right\}_{\mathrm{k} \geq 0}$ is a decreasing sequence, that is, $\forall \mathrm{k} \leq \mathrm{s}$ we have

$\Upsilon(\mathrm{K}, \epsilon) \subset \Upsilon^{\mathrm{s}}(\mathrm{K}, \epsilon) \subset \Upsilon^{\mathrm{k}}(\mathrm{K}, \epsilon)$.

Proposition 1. The set $Y(K, \epsilon)$ of some gain matrix $K$ is
(i) Convex
(ii) Symmetric,
(iii) Contain the origin in its interior,
(iv) Closed.

Proof. (i), (ii) and (iii) from the definition of $\Upsilon(\mathrm{K}, \epsilon)$

(iv) We define for each $\mathrm{k} \in \mathbb{N}$ the function $\mathrm{T}_{\mathrm{k}}$ as

$$
\begin{aligned}
\mathrm{T}_{\mathrm{k}}: \mathbb{R}^{\mathrm{n}} & \rightarrow \mathbb{R}^{\mathrm{p}} \\
\mathrm{x} & \mapsto \mathrm{CG}_{\mathrm{k}} \mathrm{x} .
\end{aligned}
$$

Then

$\Upsilon(\mathrm{K}, \epsilon)=\bigcap_{\mathrm{k} \geq 0} \mathrm{~T}_{\mathrm{k}}^{-1}(\mathrm{~B}(0, \epsilon))$

where $\mathrm{B}(0, \epsilon)=\left\{\mathrm{x} \in \mathbb{R}^{\mathrm{p}} /\|\mathrm{x}\| \leq \epsilon\right\}$.

Since $\mathrm{B}(0, \epsilon)$ is closed and $\left(\mathrm{T}_{\mathrm{k}}\right)_{\mathrm{k} \geq 0}, \mathrm{k} \in \mathbb{N}$ are continuous functions, then $\mathrm{T}_{\mathrm{k}}^{-1}(\mathrm{~B}(0, \epsilon)), \mathrm{k} \in \mathbb{N}$ are closed. Therefore $\Upsilon(K, \epsilon)$ is closed.

We give a necessary condition ensuring the finite determination of the set $Y(K, \epsilon)$ and then the set $\chi\left(\hat{\tau}_{0}, \epsilon\right)$.

Proposition 2. If $\Upsilon(K, \epsilon)$ is finitely determined, then there exists an integer $k^{*}$ such that $Y^{k^{*}}(K, \epsilon)=Y^{k^{*}+1}(K, \epsilon)$.

Proof. Suppose $\Upsilon(\mathrm{K}, \epsilon)$ is finitely determined. Then

$\exists \mathrm{k} \in \mathbb{N}, \quad \Upsilon(\mathrm{K}, \epsilon)=\Upsilon^{\mathrm{k}}(\mathrm{K}, \epsilon)$.

On the other hand

$\Upsilon^{\mathrm{k}}(\mathrm{K}, \epsilon)=\Upsilon(\mathrm{K}, \epsilon) \subset \Upsilon^{\mathrm{k}+1}(\mathrm{~K}, \epsilon) \subset \Upsilon^{\mathrm{k}}(\mathrm{K}, \epsilon)$

since $\left\{Y^{\mathrm{k}}(\mathrm{K}, \epsilon)\right\}_{\mathrm{k} \geq 0}$ is a decreasing sequence.

This leads to

$\Upsilon^{\mathrm{k}}(\mathrm{K}, \epsilon)=\Upsilon^{\mathrm{k}+1}(\mathrm{~K}, \epsilon), \quad$ for some $\mathrm{k} \geq 0$

which completes the proof
An efficient result is then introduced that permits us to determine the set $\Upsilon(K, \epsilon)$ through a finite number of inequations and then the set $\chi\left(\hat{\tau}_{0}, \epsilon\right)$ leads also to the generation of an algorithmic approach to obtain admissibility index $\mathrm{k}^{*}$. In our study, we consider two cases:

First case: $\mathrm{p}=\mathrm{n}$ (i.e. the observation space and the state space have the same dimension).

Second case: $\mathrm{p}<\mathrm{n}$.

First case, $\mathrm{p}=\mathrm{n}$. In this case $\mathrm{C}$ is an $\mathrm{n} \times \mathrm{n}$ matrix.

Proposition 3. Suppose the following assumptions hold:

(i) $\sum_{j=0}^{L}\left\|A_{j}\right\| \leq 1$ and $\Upsilon^{k}(K, \epsilon)=\Upsilon^{k+1}(K, \epsilon)$ for some $k$,

(ii) $C$ commutes with $A_{j}$ for all $0 \leq j \leq L$.

Then $Y(K, \epsilon)$ is finitely determined.

Proof. Clearly $\Upsilon(\mathrm{K}, \epsilon) \subset \Upsilon^{\mathrm{k}}(\mathrm{K}, \epsilon)$. Let $\mathrm{x}_{0} \in \Upsilon^{\mathrm{k}}(\mathrm{K}, \epsilon)$, then

$\left\|\mathrm{CG}_{\mathrm{i}} \mathrm{x}_{0}\right\| \leq \epsilon, \quad \forall \mathrm{i} \leq \mathrm{k}+1$.

But

$\left\|C G_{k+2} x_{0}\right\|=\left\|C\left(\sum_{j=0}^{L} A_{j} G_{k+1-j}\right) x_{0}\right\|$

$=\left\|\sum_{\mathrm{j}=0}^{\mathrm{L}}\left(\mathrm{CA}_{\mathrm{j}} \mathrm{G}_{\mathrm{k}+1-\mathrm{j}} \mathrm{x}_{0}\right)\right\|$

$=\left\|\sum_{j=0}^{L}\left(A_{j} C G_{k+1-j} x_{0}\right)\right\|$

$\leq \sum_{\mathrm{j}=0}^{\mathrm{L}}\left\|\mathrm{A}_{\mathrm{j}}\right\|\left\|\mathrm{CG}_{\mathrm{k}+1-\mathrm{j}} \mathrm{x}_{0}\right\|$

$\leq \epsilon \sum_{j=0}^{L}\left\|A_{j}\right\|$

since $\left\|\mathrm{CG}_{\mathrm{k}+1-\mathrm{j}} \mathrm{x}_{0}\right\| \leq \epsilon, \quad \forall \mathrm{j} \in \sigma_{0}^{\mathrm{L}}$.

Now, using the assumption $\sum_{j=0}^{L}\left\|A_{j}\right\| \leq 1$; it follows that

$\left\|\mathrm{CG}_{\mathrm{k}+2} \mathrm{x}_{0}\right\| \leq \epsilon$

By iteration, we show that

$\left\|\mathrm{CG}_{\mathrm{k}+\mathrm{j}} \mathrm{x}_{0}\right\| \leq \epsilon, \quad \forall \mathrm{j} \geq 2$

That is,

$\left\|\mathrm{CG}_{\mathrm{i}} \mathrm{x}_{0}\right\| \leq \epsilon, \quad \forall \mathrm{i} \geq \mathrm{k}+2$.

Consequently,

$\left\|\mathrm{CG}_{\mathrm{i}} \mathrm{x}_{0}\right\| \leq \epsilon, \quad \forall \mathrm{i} \geq 0$

This leads to

$\mathrm{x}_{0} \in \Upsilon(\mathrm{K}, \epsilon)$

and complete the proof.

Second case: $\operatorname{dim} B(0, \epsilon)=p<n$.

Since the matrix $C \in \mathcal{L}\left(\mathbb{R}^{n}, \mathbb{R}^{p}\right)$, we define $\widehat{C}$ and $\widehat{B}(0, \epsilon)$ as

$\widehat{\mathrm{C}}=\left(\begin{array}{l}\mathrm{C} \\ 0\end{array}\right) \in \mathcal{L}\left(\mathbb{R}^{\mathrm{n}}, \mathbb{R}^{\mathrm{n}}\right)$ 
$\widehat{\mathrm{B}}(0, \epsilon)=\mathrm{B}(0, \epsilon) \times\left\{0_{\mathbb{R}^{\mathrm{n}}-\mathrm{p}}\right\} \subset \mathbb{R}^{\mathrm{n}}$.

Now considering the new observation $\hat{y}_{i}=\hat{C} x_{i}$, we easily verify that, for every integer i

$\mathrm{y}_{\mathrm{i}} \in \mathrm{B}(0, \epsilon) \Leftrightarrow \hat{\mathrm{y}}_{\mathrm{i}} \in \widehat{\mathrm{B}}(0, \epsilon)$.

Remark 6 The set $\Upsilon(\mathrm{K}, \epsilon)$ associated to $\mathrm{C}$ and $\mathrm{B}(0, \epsilon)$ is equal to the set $\Upsilon(\mathrm{K}, \epsilon)$ associated to $\widehat{\mathrm{C}}$ and $\widehat{\mathrm{B}}(0, \epsilon)$.

Since $\operatorname{dim} \widehat{B}(0, \epsilon)=\mathrm{n}$, then the result of the first case can be applied to deduce the following proposition.

Proposition 4. Suppose the following assumptions hold:

(i) $\sum_{j=0}^{L}\left\|A_{j}\right\| \leq 1$ and $\gamma^{k}(K, \epsilon)=\gamma^{k+1}(K, \epsilon)$ for some $k$

(ii) $\hat{C}$ commutes with $A_{j}$ for all $0 \leq j \leq L$.

Then $Y(K, \epsilon)$ is finitely determined.

Proposition 5. If $\left\|G_{k}\right\| \leq \eta_{k}, \quad \forall k \geq 0$ with $\eta_{k} \rightarrow 0$ as $k \rightarrow \infty$ then $Y(K, \epsilon)$ is finitely determined.

Proof. Let $\mathrm{k} \in \mathbb{N}$ and $\mathrm{x} \in \mathbb{R}^{\mathrm{n}}$. Then

$\left\|\mathrm{CG}_{\mathrm{k}} \mathrm{x}\right\| \leq\|\mathrm{C}\|\left\|\mathrm{G}_{\mathrm{k}}\right\|\|\mathrm{x}\|$

$\leq \eta_{\mathrm{k}}\|\mathrm{C}\|\|\mathrm{x}\|$

And since $\eta_{\mathrm{k}}$ converges to zero when $\mathrm{k} \rightarrow \infty$ we deduce that

$\left\|\mathrm{CG}_{\mathrm{k}} \mathrm{x}\right\| \leq \epsilon, \quad \forall \mathrm{k} \geq \mathrm{k}_{0} \quad$ for certain $\quad \mathrm{k}_{0} \geq 0$.

$$
\text { Let } \mathrm{x}_{0} \in \Upsilon^{\mathrm{k}_{0}}(\mathrm{~K}, \epsilon) \text {. Then }
$$

$\left\|\mathrm{CG}_{\mathrm{i}} \mathrm{x}_{0}\right\| \leq \epsilon, \quad \forall \mathrm{i} \in \sigma_{0}^{\mathrm{k}_{0}}$

using this time Eq. (33) we obtain

\| $\mathrm{CG}_{\mathrm{k}_{0}+1} \mathrm{x}_{0} \| \leq \epsilon$ since $\mathrm{k}_{0}+1 \geq \mathrm{k}_{0}$.

Hence

$\mathrm{x}_{0} \in \Upsilon^{\mathrm{k}_{0}+1}(\mathrm{~K}, \epsilon)$

which completes the proof.

\section{ALGORITHMIC DETERMINATION}

As a direct consequence of Propositions 3 and 4, we propose in this section a procedure to determine $\mathrm{k}^{*}$, index of admissibility, and consequently the sets $\Upsilon(\mathrm{K}, \epsilon)$ and $\chi\left(\hat{\tau}_{0}, \epsilon\right)$.

Let $\mathbb{R}^{p}$ be endowed with the following norm:

$\|\mathrm{x}\|_{\infty}=\max _{1 \leq \mathrm{i} \leq \mathrm{p}}\left|(\mathrm{x})_{\mathrm{i}}\right|, \quad \forall \mathrm{x} \in \mathbb{R}^{\mathrm{p}}$.

We remark that

$\Upsilon^{\mathrm{k}}(\mathrm{K}, \epsilon)=\Upsilon^{\mathrm{k}+1}(\mathrm{~K}) \Leftrightarrow \Upsilon^{\mathrm{k}}(\mathrm{K}, \epsilon) \subset \Upsilon^{\mathrm{k}+1}(\mathrm{~K}, \epsilon)$

since $\Upsilon^{\mathrm{k}+1}(\mathrm{~K}, \epsilon) \subset \Upsilon^{\mathrm{k}}(\mathrm{K}, \epsilon)$.

Thus

$$
\begin{aligned}
& Y^{\mathrm{k}}(\mathrm{K}, \epsilon)=\Upsilon^{\mathrm{k}+1}(\mathrm{~K}, \epsilon) \\
& \Leftrightarrow \forall \mathrm{x} \in \Upsilon^{\mathrm{k}}(\mathrm{K}, \epsilon), \quad\left\|C G_{\mathrm{k}+1} \mathrm{x}\right\|_{\infty} \leq \epsilon \\
& \Leftrightarrow \forall \mathrm{x} \in \Upsilon^{\mathrm{k}}(\mathrm{K}, \epsilon), \quad\left|\left(\mathrm{CG}_{\mathrm{k}+1} \mathrm{x}\right)_{\mathrm{j}}\right|-\epsilon \leq 0, \forall \mathrm{j} \in \sigma_{1}^{\mathrm{p}} \\
& \Leftrightarrow \quad \sup _{\left|\left(C G_{\mathrm{i}} \mathrm{x}\right)_{1}\right|-\epsilon \leq 0, \forall l \in \sigma_{1}^{\mathrm{p}}, \forall \mathrm{i} \in \sigma_{1}^{\mathrm{k}}}\left|\left(\mathrm{CG}_{\mathrm{k}+1} \mathrm{x}\right)_{\mathrm{j}}\right|-\epsilon \leq 0, \quad \forall \mathrm{j} \in \sigma_{1}^{\mathrm{p}} . \\
& \text { This leads to the following algorithm. }
\end{aligned}
$$

Algorithm: Determination of $\mathrm{k}^{*}$

Require $n, p, L \in \mathbb{N}^{*}, C, G_{i}, \epsilon>0$

$\mathrm{k} \leftarrow 0$ for $j=1, \ldots, p$ do

Maximise $\mathrm{J}_{\mathrm{j}}(\mathrm{x})=\left|\left(\mathrm{CG}_{\mathrm{k}+1} \mathrm{x}\right)_{\mathrm{j}}\right|-\epsilon$

Subjet to the constraints $\left\{\begin{array}{l}\left|\left(\mathrm{CG}_{\mathrm{i}} \mathrm{x}\right)_{1}\right|-\epsilon \leq 0 \\ \forall \mathrm{l} \in \sigma_{1}^{\mathrm{p}}, \quad \forall \mathrm{i} \in \sigma_{0}^{\mathrm{k}} .\end{array}\right.$

end for

$\mathrm{J}_{\mathrm{j}}^{*} \leftarrow \max \left\{\mathrm{J}_{\mathrm{j}}(\mathrm{x})\right\}$

if $\mathrm{J}_{\mathrm{j}}^{*} \leq 0, \forall \mathrm{j}=1,2, \ldots, \mathrm{p}$ then

$\mathrm{k}^{*} \leftarrow \mathrm{k}$

else

$\mathrm{k} \leftarrow \mathrm{k}+1$ and return to for

end else

Remark 7 The hypothesis of Proposition 5 in section (3) is sufficient but not necessary. If this condition is not provided, the stopping of the algorithm is not certain. The maximal output set $\Upsilon(\mathrm{K}, \epsilon)$ is finitely determined and then the set $\chi\left(\hat{\tau}_{0}, \epsilon\right)$ if the algorithm converges, otherwise it is not.

\section{NUMERICAL EXAMPLES}

To demonstrate our achieved results, we present in the following section some examples in the two-dimensional case. We will determine the set $Y_{\epsilon}(K)$ and then the set $\chi\left(\hat{\tau}_{0}, \epsilon\right)$ as a finite number of inequations using our algorithm. Assuming

$\sum_{\mathrm{j}=0}^{\mathrm{L}}\left\|\mathrm{A}_{\mathrm{j}}\right\|<1$

is checked in all the introduced examples, we will select the gain matrix $\mathrm{K}$ such that this condition (34) is verified.

Using the property that (Hilfer, 2000)

$\sum_{j=0}^{L}(-1)^{j}\left(\begin{array}{l}\alpha \\ j\end{array}\right)=\frac{\Gamma(L+1-\alpha)}{\Gamma(1-\alpha) \Gamma(L+1)}$

and the fact that

$\sum_{\mathrm{j}=0}^{\mathrm{L}}\left\|\mathrm{A}_{\mathrm{j}}\right\|=\left\|\mathrm{A}+\mathrm{BK}+\alpha \mathrm{I}_{\mathrm{n}}\right\|-\sum_{\mathrm{j}=2}^{\mathrm{L}}(-1)^{\mathrm{j}}\left(\begin{array}{l}\alpha \\ \mathrm{j}\end{array}\right)+$

$\left|\left(\begin{array}{l}\alpha \\ L+1\end{array}\right)\right|$

we deduce that the condition $\sum_{\mathrm{j}=0}^{\mathrm{L}}\left\|\mathrm{A}_{\mathrm{j}}\right\|<1$ can be rewritten as follows:

$\left\|\mathrm{A}+\mathrm{BK}+\alpha \mathrm{I}_{\mathrm{n}}\right\|-\sum_{\mathrm{j}=2}^{\mathrm{L}}(-1)^{\mathrm{j}}\left(\begin{array}{l}\alpha \\ \mathrm{j}\end{array}\right)+\left|\left(\begin{array}{l}\alpha \\ \mathrm{L}+1\end{array}\right)\right|<1$

For example, for $\mathrm{L}=50$ and $\alpha=0.4$, we have

$\sum_{\mathrm{j}=0}^{\mathrm{L}}\left\|\mathrm{A}_{\mathrm{j}}\right\|=\left\|\mathrm{A}+\mathrm{BK}+\alpha \mathrm{I}_{\mathrm{n}}\right\|+0.4610$.

Then the matrix $\mathrm{K}$ must select such that

$\left\|\mathrm{A}+\mathrm{BK}+\alpha \mathrm{I}_{\mathrm{n}}\right\|<0.5390$.

The dotted region will indicate the set $\Upsilon_{\epsilon}(K, \epsilon)$.

Example 1. Let us consider the following system:

$$
\left\{\begin{array}{l}
x_{i+1}=\sum_{j=0}^{i} A_{j} x_{i-j} \\
x_{0}=\tau_{0}+\hat{\tau}_{0} \in \mathbb{R}^{2}
\end{array}\right.
$$


where $\tau_{0}$ and $\hat{\tau}_{0}$ are the known and unknown parts of the initial state, respectively.

Let $A, B, C, \alpha, \epsilon$ and $L$ be defined as

$$
\begin{aligned}
& A=\left(\begin{array}{cc}
-1.25 & \frac{11}{24} \\
\frac{5}{12} & -\frac{8}{7}
\end{array}\right), \quad B=\left(\begin{array}{ll}
2 & -\frac{1}{3} \\
-\frac{1}{2} & 1
\end{array}\right) \\
& C=\left(\begin{array}{ll}
1 & 2
\end{array}\right), \quad \alpha=0.7, \quad \epsilon=0.7, \quad L=20 .
\end{aligned}
$$

We have

$A_{j}=-(-1)^{j+1}\left(\begin{array}{l}0.7 \\ j+1\end{array}\right) I_{2}, \quad \forall j \in\{1,2, \ldots, L\}$.

We select the gain matrix $\mathrm{K}$ such that $\left\|\mathrm{A}_{0}\right\|<0.7395$ (since $\left.\sum_{j=1}^{20}\left\|A_{j}\right\|=0.2605\right)$. For $K=\left(\begin{array}{ll}0.5 & 0 \\ 0 & 1\end{array}\right)$, we have

$\widetilde{A}=A+B K=\left(\begin{array}{ll}-\frac{1}{4} & \frac{1}{8} \\ \frac{1}{6} & -\frac{1}{7}\end{array}\right)$

$\mathrm{A}_{0}=\widetilde{\mathrm{A}}+\alpha \mathrm{I}_{2}=\left(\begin{array}{ll}\frac{9}{20} & \frac{1}{8} \\ \frac{1}{6} & \frac{39}{70}\end{array}\right)$

and

$\sum_{j=0}^{20}\left\|A_{j}\right\|=\left\|A_{0}\right\|+\sum_{j=1}^{20}\left\|A_{j}\right\|=0.9426<1$

where $\left\|A_{0}\right\|=\max _{1 \leq j \leq 2} \sum_{i=1}^{2}\left|\left(A_{0}\right)_{i j}\right|$.

In this example, we take $\tau_{0}$ that belongs to a hexagon (a polygon with six sides), see Fig. 1.

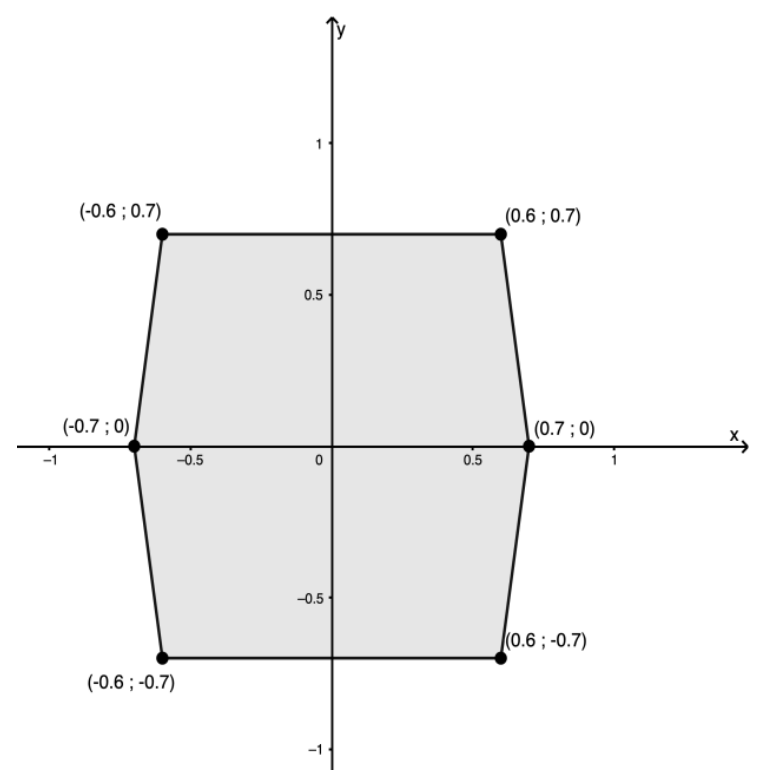

Fig. 1. The set $\Omega$ with vertices $\mathrm{w}_{1}, \mathrm{w}_{2}, \ldots, \mathrm{w}_{6}$.

$\mathrm{CG}_{0}\left(\begin{array}{l}\mathrm{X} \\ \mathrm{y}\end{array}\right), \ldots, \mathrm{CG}_{5}\left(\begin{array}{l}\mathrm{X} \\ \mathrm{y}\end{array}\right)$ are given by:
$\mathrm{CG}_{0}\left(\begin{array}{l}\mathrm{x} \\ \mathrm{y}\end{array}\right)=\mathrm{x}+2 \mathrm{y}$

$\mathrm{CG}_{1}\left(\begin{array}{l}\mathrm{x} \\ \mathrm{y}\end{array}\right)=\frac{47}{60} \mathrm{x}+\frac{347}{280} \mathrm{y}$

$\mathrm{CG}_{2}\left(\begin{array}{l}\mathrm{x} \\ \mathrm{y}\end{array}\right)=\frac{2789}{4200} \mathrm{x}+\frac{117409}{117600} \mathrm{y}$

$\mathrm{CG}_{3}\left(\begin{array}{l}\mathrm{x} \\ \mathrm{y}\end{array}\right)=\frac{2091989}{3528000} \mathrm{x}+\frac{7082557}{8232000} \mathrm{y}$

$\mathrm{CG}_{4}\left(\begin{array}{l}\mathrm{x} \\ \mathrm{y}\end{array}\right)=\frac{267585763}{493920000} \mathrm{x}+\frac{5303791039}{6914880000} \mathrm{y}$

$\mathrm{CG}_{5}\left(\begin{array}{l}\mathrm{x} \\ \mathrm{y}\end{array}\right)=\frac{260274628301}{518616000000} \mathrm{x}+\frac{3377530607827}{4840416000000} \mathrm{y}$.

Using our algorithm we obtain $\mathrm{k}^{*}=4$ and then

$$
\begin{aligned}
& \int|x+2 y| \leq 2 \\
& \left|\frac{47}{60} x+\frac{347}{280} y\right| \leq 2 \\
& =\left\{\left(\begin{array}{l}
x \\
y
\end{array}\right) \in \mathbb{R}^{2} \backslash\left|\frac{2789}{4200} x+\frac{117409}{117600} y\right| \leq 2,\right. \\
& \left|\frac{2091989}{3528000} x+\frac{7082557}{8232000} y\right| \leq 2 \\
& \left.\left|\frac{267585763}{493920000} x+\frac{5303791039}{6914880000} y\right| \leq 2\right)
\end{aligned}
$$

We can see that $\mathrm{w}_{1}=\left(\begin{array}{l}0.7 \\ 0\end{array}\right), \mathrm{w}_{2}=\left(\begin{array}{l}0.6 \\ 0.7\end{array}\right), \mathrm{w}_{3}=$ $\left(\begin{array}{l}-0.6 \\ 0.7\end{array}\right), \mathrm{w}_{4}=\left(\begin{array}{l}-0.7 \\ 0\end{array}\right), \mathrm{w}_{5}=\left(\begin{array}{l}-0.6 \\ -0.7\end{array}\right), \mathrm{w}_{6}=\left(\begin{array}{l}0.6 \\ -0.7\end{array}\right) \in$ $\Upsilon(\mathrm{K}, \epsilon)$. Hence, the system is insensitive to the unknown part $\hat{\tau}_{0}$. Consequently, the gain matrix $\mathrm{K} \in \chi\left(\hat{\tau}_{0}, \epsilon\right)$.

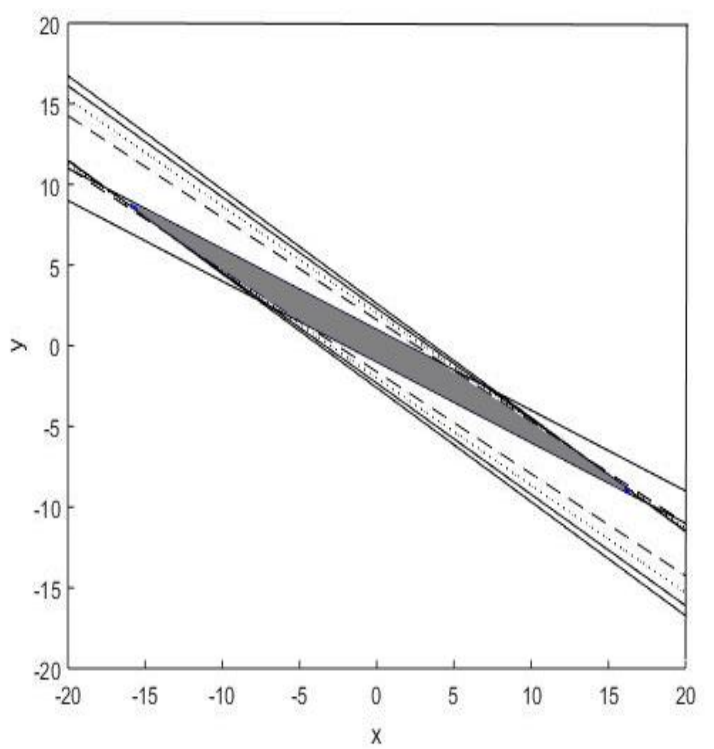

Fig. 2. The set $\Upsilon(K, \epsilon)$ corresponding to $K=\left(\begin{array}{ll}0.5 & 0 \\ 0 & 1\end{array}\right)$ and $\alpha=0.7$ 
Example 2. Consider the following system:

$$
\left\{\begin{array}{l}
x_{i+1}=\sum_{j=0}^{i} A_{j} x_{i-j} \\
x_{0}=\tau_{0}+\hat{\tau}_{0} \in \mathbb{R}^{2}
\end{array}\right.
$$

where $\tau_{0}$ and $\widehat{\tau}_{0}$ are the known and unknown parts of the initial state, respectively, and A, B, K, C, $\alpha, \epsilon$ are described as follows:

$$
\begin{aligned}
& C=\left(\begin{array}{ll}
2 & -1
\end{array}\right), \quad A=\left(\begin{array}{cc}
\frac{8}{7} & \frac{2}{3} \\
-\frac{17}{30} & -\frac{2}{9}
\end{array}\right) \\
& B=\left(\begin{array}{c}
-0.5 \\
\frac{1}{3}
\end{array}\right), \quad \alpha=0.2, \quad \epsilon=0.8 .
\end{aligned}
$$

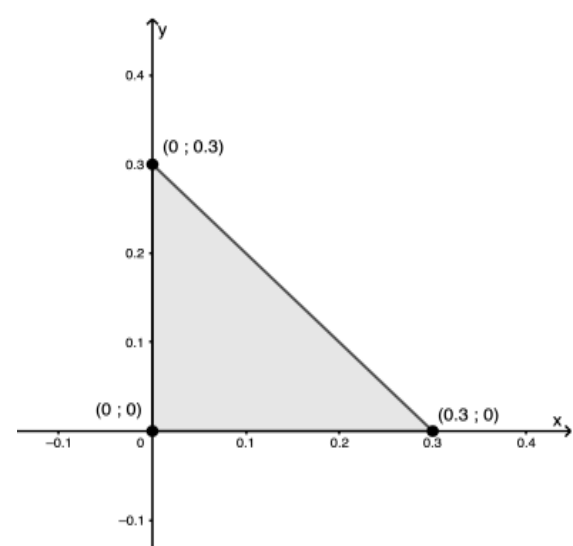

Fig. 3. The set $\Omega$ with vertice $\mathrm{w}_{1}=(0 ; 0), \mathrm{w}_{2}=(0.3 ; 0)$, $\mathrm{w}_{3}=(0 ; 0.3)$.

In this example, the memory length $\mathrm{L}$ is equal to 30 and we assume $\tau_{0}$ to belong to a triangle (see Fig. 3 ). The matrices $A_{j}$ are given as

$\mathrm{A}_{0}=\widetilde{\mathrm{A}}+\alpha \mathrm{I}_{2}=\mathrm{A}+\mathrm{BK}+\alpha \mathrm{I}_{2}$

and

$A_{j}=-(-1)^{j+1}\left(\begin{array}{l}\alpha \\ j+1\end{array}\right) I_{3}, \quad j=1, \ldots, L$.

We select the gain matrix $\mathrm{K}$ such that $\left\|\mathrm{A}_{0}\right\|<0.6311$ (since $\left.\sum_{j=1}^{30}\left\|A_{j}\right\|=0.3689\right)$. For $K=\left(\begin{array}{ll}2 & 1\end{array}\right)$ we have

$\mathrm{A}_{0}=\left(\begin{array}{cc}\frac{12}{35} & \frac{1}{6} \\ \frac{1}{10} & \frac{14}{45}\end{array}\right)$

and

$\sum_{j=0}^{30}\left\|A_{j}\right\|=\left\|A_{0}\right\|+\sum_{j=1}^{30}\left\|A_{j}\right\|=0.8467<1$

where $\left\|\mathrm{A}_{0}\right\|=\max _{1 \leq \mathrm{j} \leq 2} \sum_{\mathrm{i}=1}^{2}\left|\left(\mathrm{~A}_{0}\right)_{\mathrm{ij}}\right|$.

On the other hand, we have

$\mathrm{CG}_{0}\left(\begin{array}{l}\mathrm{x} \\ \mathrm{y}\end{array}\right)=\left(\begin{array}{ll}2 & -1\end{array}\right)\left(\begin{array}{l}\mathrm{x} \\ \mathrm{y}\end{array}\right)=2 \mathrm{x}-\mathrm{y}$
$\mathrm{CG}_{1}\left(\begin{array}{l}\mathrm{X} \\ \mathrm{y}\end{array}\right)=\left(\begin{array}{ll}2 & -1\end{array}\right)\left(\begin{array}{cc}\frac{12}{35} & \frac{1}{6} \\ \frac{1}{10} & \frac{14}{45}\end{array}\right)\left(\begin{array}{l}\mathrm{x} \\ \mathrm{y}\end{array}\right)=\frac{41}{70} \mathrm{x}+\frac{1}{45} \mathrm{y}$

$\mathrm{CG}_{2}\left(\begin{array}{l}\mathrm{x} \\ \mathrm{y}\end{array}\right)=\left(\begin{array}{ll}2 & -1\end{array}\right)\left(\begin{array}{ll}\frac{3149}{14700} & \frac{103}{945} \\ \frac{103}{1575} & \frac{1567}{8100}\end{array}\right)\left(\begin{array}{l}\mathrm{x} \\ \mathrm{y}\end{array}\right)=\frac{1601}{4410} \mathrm{x}+\frac{1391}{56700} \mathrm{y}$

$\mathrm{CG}_{3}\left(\begin{array}{l}\mathrm{x} \\ \mathrm{y}\end{array}\right)=\left(\begin{array}{ll}2 & -1\end{array}\right)\left(\begin{array}{ll}\frac{369917}{2315250} & \frac{197527}{2381400} \\ \frac{197527}{3969000} & \frac{91838}{637875}\end{array}\right)\left(\begin{array}{l}\mathrm{x} \\ \mathrm{y}\end{array}\right)=$

$\frac{7495319}{27783000} \mathrm{x}+\frac{391441}{17860500} \mathrm{y}$.

We have used the relation $G_{k}=\sum_{j=0}^{L} A_{j} G_{k-1-j}, k \geq 1$ to find the matrices $\mathrm{G}_{\mathrm{k}}$. Using our algorithm we obtain $\mathrm{k}^{*}=1$ and then the set $\Upsilon(K, \epsilon)$

$$
\Upsilon(\mathrm{K}, \epsilon)=\left\{\begin{array}{l}
\left(\begin{array}{l}
\mathrm{x} \\
\mathrm{y}
\end{array}\right) \in \mathbb{R}^{2} \backslash \\
|2 \mathrm{x}-\mathrm{y}| \leq 0.8 \\
\left|\frac{41}{70} \mathrm{x}+\frac{1}{45} \mathrm{y}\right| \leq 0.8
\end{array}\right\} .
$$

Since $\mathrm{w}_{1}=\left(\begin{array}{l}0 \\ 0\end{array}\right), \mathrm{w}_{2}=\left(\begin{array}{l}0.3 \\ 0\end{array}\right), \mathrm{w}_{1}=\left(\begin{array}{l}0 \\ 0.3\end{array}\right) \in \Upsilon(\mathrm{K}, \epsilon)$, we deduce that the unknown part $\hat{\tau}_{0}$ does not influence the associated output function. In this case, the chosen matrix $\mathrm{K}$ belongs to $\chi\left(\hat{\tau}_{0}, \epsilon\right)$, so it is useful.

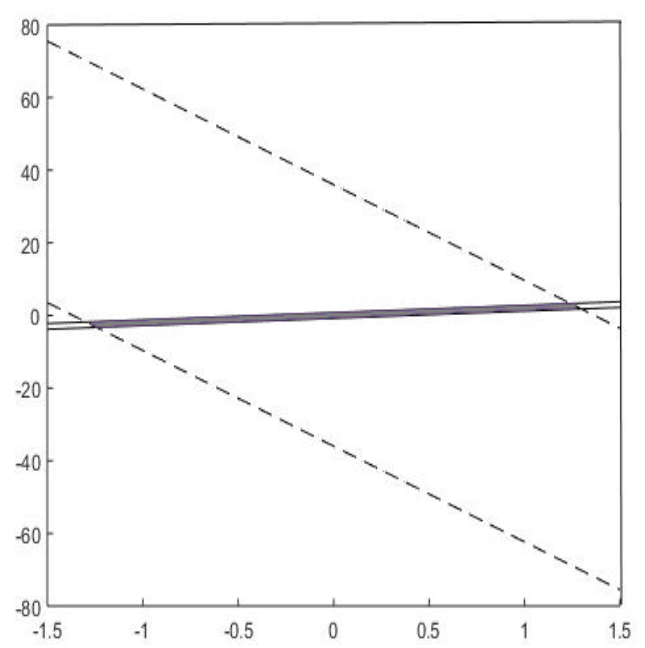

Fig. 4. The set $\Upsilon(K, \epsilon)$ is associated to $K=\left(\begin{array}{ll}2 & 1\end{array}\right)$ and $\alpha=0.2$.

Example 3. For

$$
\begin{aligned}
& A=\left(\begin{array}{cc}
\frac{37}{12} & -\frac{15}{8} \\
\frac{1}{10} & -\frac{15}{8}
\end{array}\right), \quad B=\left(\begin{array}{ll}
3 & 1 \\
0 & 1
\end{array}\right) \\
& K=\left(\begin{array}{cc}
-1 & 0 \\
0 & 2
\end{array}\right), \quad C=\left(\begin{array}{ll}
1 & -1
\end{array}\right) \\
& \varepsilon=0.1, \quad \alpha=0.1, \quad L=8
\end{aligned}
$$

we obtain

$\mathrm{CG}_{0}\left(\begin{array}{l}\mathrm{x} \\ \mathrm{y}\end{array}\right)=\mathrm{x}-\mathrm{y}$ 


$$
\begin{aligned}
& \mathrm{CG}_{1}\left(\begin{array}{l}
\mathrm{x} \\
\mathrm{y}
\end{array}\right)=\left(\begin{array}{ll}
1 & -1
\end{array}\right)\left(\begin{array}{cc}
\frac{11}{60} & \frac{1}{8} \\
\frac{1}{10} & \frac{9}{40}
\end{array}\right)\left(\begin{array}{l}
\mathrm{x} \\
\mathrm{y}
\end{array}\right)=\frac{1}{12} \mathrm{x}-\frac{1}{10} \mathrm{y} \\
& \mathrm{CG}_{2}\left(\begin{array}{l}
\mathrm{X} \\
\mathrm{y}
\end{array}\right)=\left(\begin{array}{ll}
1 & -1
\end{array}\right)\left(\begin{array}{cc}
\frac{41}{450} & \frac{49}{960} \\
\frac{49}{1200} & \frac{173}{1600}
\end{array}\right)\left(\begin{array}{l}
\mathrm{x} \\
\mathrm{y}
\end{array}\right)=\frac{181}{3600} \mathrm{x}-\frac{137}{2400} \mathrm{y} \\
& \mathrm{CG}_{3}\left(\begin{array}{l}
\mathrm{X} \\
\mathrm{y}
\end{array}\right)=\mathrm{C}\left(\begin{array}{cc}
\frac{25297}{432000} & \frac{3283}{115200} \\
\frac{3283}{144000} & \frac{13067}{192000}
\end{array}\right)\left(\begin{array}{l}
\mathrm{X} \\
\mathrm{y}
\end{array}\right)=\frac{1931}{54000} \mathrm{x}-\frac{11393}{288000} \mathrm{y} \\
& \mathrm{CG}_{4}\left(\begin{array}{l}
\mathrm{X} \\
\mathrm{y}
\end{array}\right)=\mathrm{C}\left(\begin{array}{ll}
\frac{56471173}{1296000000} & \frac{270829}{13824000} \\
\frac{270829}{17280000} & \frac{28859813}{576000000}
\end{array}\right)\left(\begin{array}{l}
\mathrm{x} \\
\mathrm{y}
\end{array}\right)= \\
& \frac{18079499}{648000000} \mathrm{x}-\frac{26362907}{864000000} \mathrm{y}
\end{aligned}
$$

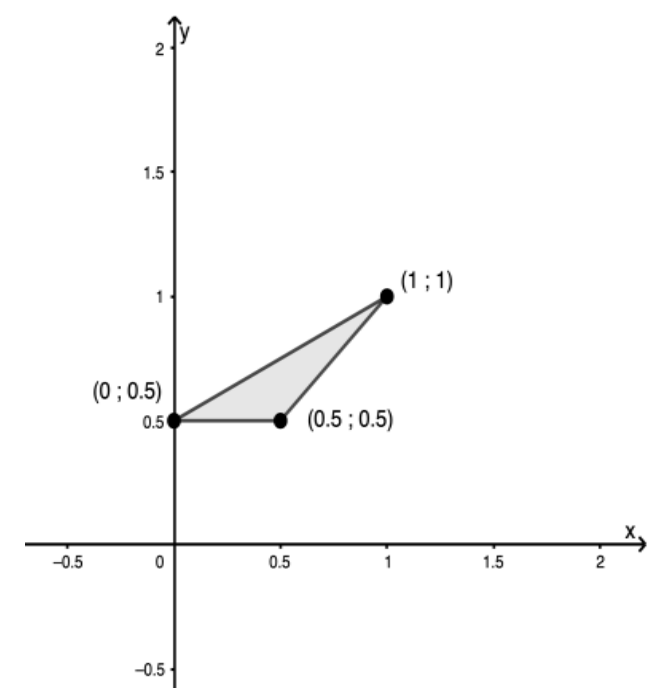

Fig. 5. The set $\Omega$ with vertices

$$
\mathrm{w}_{1}=(0.5 ; 0.5), \mathrm{w}_{2}=(0 ; 0.5), \mathrm{w}_{3}=(1 ; 1) \text {. }
$$

In this example, we assume $\tau_{0}$ belongs to a triangle (see Fig. 4). Using our algorithm, we obtain $\mathrm{k}^{*}=3$, and then the set

$$
\left\{\begin{array}{c}
\Upsilon(K, \epsilon)= \\
|\mathrm{x}-\mathrm{y}| \leq 0.1 \\
\left|\frac{1}{12} \mathrm{x}-\frac{1}{10} \mathrm{y}\right| \leq 0.1 \\
\left(\begin{array}{l}
\mathrm{x} \\
\mathrm{y}
\end{array}\right) \in \mathbb{R}^{2} /\left|\frac{181}{3600} \mathrm{x}-\frac{137}{2400} \mathrm{y}\right| \leq 0.1 \\
\left|\frac{1931}{54000} \mathrm{x}-\frac{11393}{288000} \mathrm{y}\right| \leq 0.1
\end{array}\right\}
$$

Since $w_{1}=\left(\begin{array}{l}0.5 \\ 0.5\end{array}\right), w_{2}=\left(\begin{array}{l}1 \\ 1\end{array}\right) \in \Upsilon(K, \epsilon)$ and $w_{3}=$ $\left(\begin{array}{l}0 \\ 0.5\end{array}\right) \notin \Upsilon(K, \epsilon)$, we conclude that the system is influenced by the unknown part $\hat{\tau}_{0}$. Thus $K=\left(\begin{array}{cc}-1 & 0 \\ 0 & 2\end{array}\right) \notin \chi\left(\hat{\tau}_{0}, \epsilon\right)$.

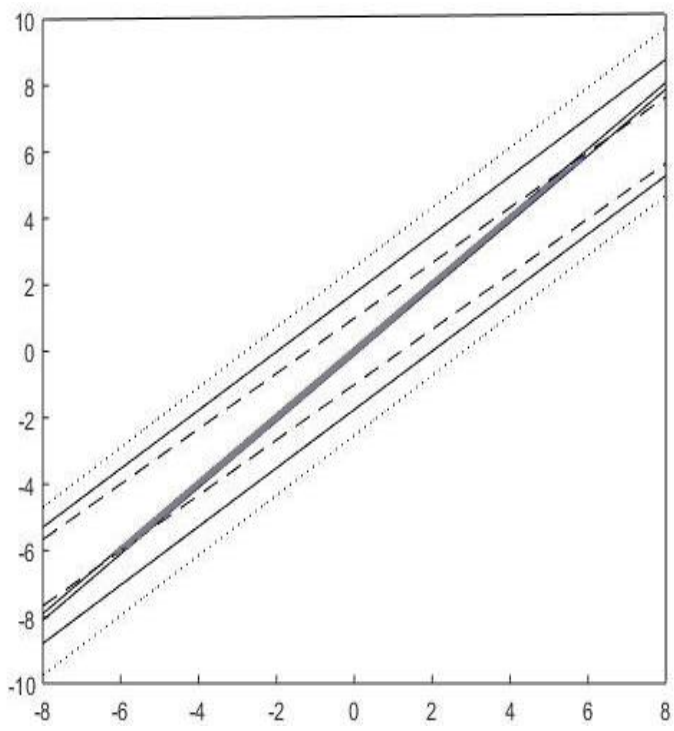

Fig. 6. The $\operatorname{set} \Upsilon(K, \epsilon)$ corresponding to $K=\left(\begin{array}{cc}-1 & 0 \\ 0 & 2\end{array}\right)$ and $\alpha=0.1$.

In examples 1-3, we have identified the set of all possible gain matrices which make the system insensitive to the unknown part $\hat{\tau}_{0}$ of the initial state $x_{0}$ via a finite number of inequations using Algorithm 1 based on the simplex method, which allow solving problems of maximisation that arise in such algorithm. In Figs. 1-3, we have traced the constraints constituting the sets $\Upsilon(\mathrm{K}, \epsilon)$.

\section{CONCLUSION}

In this paper, we have studied the problem of fractional order discrete-time controlled linear systems with unknown part of the initial state using the Grünwald-Letnikov fractional derivative. We have investigated the characterisation of the set $\chi\left(\hat{\tau}_{0}, \epsilon\right)$ of all possible gain matrices so that the sensitivity of the resulting system output would be relatively tolerable based on the study of maximal output set. Some new sufficient conditions to ensure the finite determination of $\chi\left(\hat{\tau}_{0}, \epsilon\right)$ are given. Furthermore, a useful algorithm is produced to identify the index of admissibility $\mathrm{k}^{*}$ and then the set $\chi\left(\hat{\tau}_{0}, \epsilon\right)$. The theoretical results are shown by various examples and numerical simulation. As a natural continuation of this work, we are studying the following problem.

\section{REFERENCES}

1. Abdelhak A. , M. Rachik M. (2019), Model reduction problem of linear discrete systems: Admissibles initial states, Archives of Control Sciences, volume 29(LXV), no. 1, pages 41-55, 2019.

2. Abdelilah LarracheL., Mustapha LhousL., Soukaina Ben B.RhilaR., Mostafa Rachik R. Abdessamad TridaneT. (2020), An output sensitivity problem for a class of linear distributed systems with uncertain initial state, Archives of Control Sciences, volume 30(LXVI), no. 1, pages 139-155, 2020.

3. Amine El Bhih.B., Youssef BenfatahB., Mostafa RachikR. (2020), Exact determination of maximal output admissible set for a class of semilinear discrete systems, Archives of Control Sciences, ACS volume 30(LXVI), no. 3, pages 523-552, 10.24425/acs.2020.134676, 2020. 
4. Andrzej Dzielinski A., and Dominik Sierociuk D. (2008), Stability of Discrete Fractional Order State-space Systems. Journal of Vibration and Control, 14: 1543, 2008.

5. Arild Thomson A. (2007), International journal of systems science, Identifiability of dynamic systems, volume 9, pages $813-825$, Issue 2007.

6. Balatif, O., Rachik, M., Labriji, E. houssine, Rachik, Z. (2016). ), Optimal control problem for a class of bilinear systems via block pulse functions. IMA Journal of Mathematical Control and Information, dnw005. doi:10.1093/imamci/dnw005.

7. Buslowicz M. (1983), On some properties of the solution of state equation of discrete-time systems with delays, Zesz.Nauk. Polit. Bial., Elektrotechnika, vol. 1, pp. 17-29, 1983 in Polish.

8. Chi-Tsong ehenE. (2008), Analog and Digital control system design transfer-function, state space, Algebraic Methods. State University of New York at Stony Broak, Springer 2008.

9. Chraïbi, L., Karrakchou, J., Rachik, M., Ouansafi, A. (2006),. Linear quadratic control problem with a terminal convex constraint for discrete-time distributed systems. IMA Journal of Mathematical Control and Information, 23(3), 347-370. doi:10.1093/imamci/dni063.

10. D.W.Gu D.W., P.Hr.Petkov P.Hr. and, M.M.Konstantinov M.M. (2005), Robust control design with Matlab, Springer $2005 .$.

11. Debnath L. (2003. ), Recent Applications of Fractional Calculus to Science and Engineering. IJMMS, Hindawi Publishing, volume 54, pp. 3413-3442, 2003.

12. Dórea, C. E. T., and Hennet, J. C. (1996), Computation of Maximal Admissible Sets of Constrained Linear Systems, Proceedings of the 4th IEEE Mediterranean Symposium on New Directions on Control and Automation, Maleme, Greece, pp. 286291, 1996.

13. Dzieliński and A.D., Sierociuk D. (2005), Adaptive Feedback Control of Fractional Order Discrete-Time State-Space Systems. Proceedings of the 2005 International Conference on Computational Intelligence for Modelling, Control and Automation, and International Conference on Intelligent Agents, Web Technologies and Internet Commerce, CIMCA-IAWTIC'05, 2005.

14. Ferreira, R.A.C., and Torres, D.F.M. (2011), Fractional hDifference Equations Arising from the Calculus of Variations, Applicable Analysis and Discrete Mathematics, 5, 110-121, 2011.

15. Franklin (2001), Feedback control of dynamic systems, 5th edition, springer 2001.

16. Gilbert E. G. and , Tan K. T. (1991), Linear systems with state and control constraints: the theory and application of maximal output admissible sets, in IEEE Transactions on Automatic Control, vol. 36, no. 9, pp. 1008-1020, Sept 1991.

17. Haim BrezisB., Functional Analysis, Sobolev Spaces and Partial Differential Equations, ISBN 978-0-387-70913-0, doi:10.1007/978-0387-70914-7.

18. Hilfer, R., ed. (2000), Application of Fractional Calculus in Physics, World Scientific, Singapore, 2000.

19. J.L.Lions J.L. (1988, ), Sur les sentinelles des systèmes distribués.C.R.A.S. Paris, t. 307. Le cas des conditions initiales incomplètes, p. 819-893. Conditions frontières, termes sources. coefficients incomplètement connus, p.865-870, 1988.

20. Joycer OsorioO., Hamid R. OssarehO. (2018), A Stochastic Approach to Maximal Output Admissible Sets and Reference Governors, Control Technology and Applications (CCTA) 2018 IEEE Conference on, pp. 704-709, 2018.

21. Kaczorek, T. (2007), Reachability and Controllability to Zero of Cone Fractional Discrete-time Systems, Archives of Control Sciences, 17, 357-367, 2007.

22. Kaczorek, T. (2008), Reachability of Fractional Positive Continuoustime Linear Systems, International Journal of Applied Mathematics and Computer Science, 18, 223-228, 2008.
23. Kauffmann. M, Bretthawer. G., Identifiability of the linear closed loop systems, Control Systems, Robotics and Automation, volume V, pages 127-138.

24. Kilbas A. A., Srivastava H. M. and , Trujillo. J. J. (2006), Theory and Application of Fractional Differential Equations North Holland Mathematics Studies, Editor Jan van Mill, Elsevier, 2006.

25. Kolmanovsky I., Gilbert E.G. (1998), Theory and computation of disturbance invariance sets for discrete-time linear systems, Mathematical Problems in Engineering: Theory, Methods and Applications, vol. 4, pp. 317-367, 1998.

26. Lions J.L. (1992), Sentinelles pour les systèmes distribués à données incomplètes, Recherches en Mathematiques Appliquées 21, Masson, Paris, 1992.

27. Lions, J.L. (1988), Sentinels for periodic distributed systems. Chinese Annals of Math B. Vol. 10. p 213-225.

28. Namerikawa T., W. Shinozuka W. , and M., Fujita M. (2004), Disturbance and Initial State Uncertainty Attenuation Control for Magnetic Bearings, In Proceedings 9th International Symposium on Magnetic Bearings, pp. 3-6, $2004 .$.

29. Ogata Katsuhiko O. (1995), Discrete time control systems, Prentice Hall internatiounal editions 1995.

30. Oldham K. B. and ., J. Spanier J. (1974),. The Fractional Calculus. Academic Press, 1974.

31. Podlubny I. (1999), Fractional Differential Equations. Academic Press, 1999.

32. Rachik M., M. Lhous M., A. Tridane A. (2002), On the Maximal Output Admissible Set for a Class of Nonlinear Discrete Systems, Systems Analysis Modelling Simulation, 42:11, 1639-1658, DOI: 10.1080/716067174.

33. Rachik, M., Lhous, M. (2016), An observer-based control of linear systems with uncertain parameters. Archives of Control Sciences, 26(4), 565-576. doi:10.1515/acsc-2016-0031, 2016.

34. Robert L.Payne R.L., Graham C.GoodwinG. (2007), International journal of control, On the identifiability of linear systems, volume 20 , Issues 5, 2007, pages 865-868.

35. Rosario ToscanoT. (2005), Commande et diagnostic des systèmes dynamiques, Ellipses 2005..

36. Sawadogo S. (2020), Control of a migration problem of a population by the sentinel method, Journal of Nonlinear Evolution Equations and Applications, Volume 2020, Number 3, pp. 37-53, March 2020.

37. Sierociuk, D., and Dzieliński, A. (2006, ), Fractional Kalman Filter Algorithm for the States, Parameters and Order of Fractional System Estimation, International Journal of Applied Mathematics and Computer Science, 16, 129-140, 2006.

38. Yamamoto K. (2019), Time-variant feedback controller based on capture point and maximal output admissible set of a humanoid, Advanced Robotics, 33:18, 944-955, 2019.

Acknowledgements: The authors would like to thank the reviewer for his time to help improve this paper. Research reported in this paper was supported by the Moroccan Systems Theory Network.

Data Availability: The disciplinary data used to support the findings of this study have been deposited in the Network Repository (http://www.networkrepository.com).

Youssef Benfatah: (ID https://orcid.org/0000-0001-9497-003X

Amine El Bhih: (D) https://orcid.org/0000-0003-0877-5882

Mostafa Rachik: (D) https://orcid.org/0000-0002-5118-2786 